\title{
REVIEW
}

\section{THE PHYLOGENY OF PLASTIDS: A REVIEW BASED ON COMPARISONS OF SMALL-SUBUNIT RIBOSOMAL RNA CODING REGIONS}

\author{
Debashish Bhattacharya ${ }^{1}$ \\ Universität zu Köln, Botanisches Instiłut, Lehrstuhl 1, Gyrhofstraße 15, 50931 KöIn, Germany \\ and \\ Linda Medlin \\ Alfred Wegener Institute for Polar and Marine Research, Am Handelshafen, 12, 27570 Bremerhaven, Germany
}

Because photosynthesis has played such a fundamental role in shaping the biosphere, the origins of the plastids have remained one of the most intriguing and well-researched topics in biology. The initial formulation of the theory of endosymbiosis as an explanation for plastid origins (Schimper 1883, Mereschkowsky 1905, 1910, Margulis 1981) has been followed by a myriad of biochemical, ultrastructural, and molecular biological analyses of these organelles. These studies have provided many important clues that, together, begin to unravel the complex evolutionary history of plastids (for reviews see Martin et al. 1992, Lewin 1993, Palmer 1993, Douglas 1994, Loiseaux-de-Goer 1994).

The vast existing body of literature on plastid endosymbiosis and evolution necessarily limits the quantity of data that may be successfully analyzed in a synopsis of this theme. We have, therefore, narrowed our focus considerably and addressed the evolutionary relationships and origin of plastids from the perspective of molecular evolutionary analyses of plastid- and nuclear-encoded small-subunit ribosomal RNA (ssu rRNA) coding regions. Analysis of plastid and "host" cell phylogenies provides a powerful tool for testing the consistency of hypotheses regarding the evolutionary relationships of plastids by direct comparison to the relationships of the host cells that contain them. Using this simple test, we expect that when plastids share a monophyletic origin within a lineage (e.g. green algae, red algae), topologies inferred from the phylogenetic analyses of plastid- and nuclear-encoded (i.e. host cell) ssu rRNAs will be approximately congruent (given that the sequences themselves do not contain extreme biases). From such comparisons, we wish to address the number and timing of the primary and secondary endosymbiotic events that have resulted in the complex array of extant plastids and discuss these findings in relation to existing ultrastructural, biochemical, and sequence data. The ssu rRNAs are

\footnotetext{
1 Present address and author for reprints: Max-Planck-Institut für biophysikalische Chemie, Abteilung Biochemie, Am Faßberg 11, 37077 Göttingen, Germany.
}

valuable markers to approach such questions because these coding regions are of a relatively large size (approx. 1400-1800 base pairs), contain variable and highly conserved regions to address both close and distant evolutionary relationships, respectively, and are of a universally conserved function with no evidence to suggest that nuclear-encoded rRNAs are laterally transferred (Woese 1987, Sogin 1991, Bhattacharya et al. 1992). A large rRNA database (e.g. the Ribosomal Database Project, Maidak et al. 1994) ensures inclusion of members of all major phyla in any analysis.

\section{Historical Perspective}

Multiple primary endosymbiotic plastid origins. The origin of the initial photosynthetic eukaryote likely involved the phagotrophic uptake of a cyanobacterium (Mereschkowsky 1905, Giovannoni et al. 1988, Douglas and Turner 1991). Differences in plastid accessory light-harvesting pigments (e.g. Chlorophyta, chlorophylls $a+b$; Rhodophyta, Glaucocystophyta, chlorophyll $a+$ phycobilins; Haptophyta, Heterokonta, and most Dinophyta, chlorophylls a $+c$; Cryptophyta, chlorophylls $a+c+$ phycobilins) suggest that the plastids in these lineages may have arisen from different cyanobacterial ancestors, each possessing a distinct complement of accessory pigments. Such a theory implies multiple primary endosymbiotic plastid origins (P. H, Raven 1970).

The discovery of the Prochlorophyta (Lewin 1976, cyanobacteria that contain chlorophylls $a+b$ and closely spaced thylakoids similar to those of green algae/land plants but that lack phycobilins) provided the first opportunity to test the hypothesis of a separate primary endosymbiotic origin of chloroplasts and other plastids. Sequence analyses of prochlorophytes suggest, however, that these taxa form a paraphyletic assemblage that is embedded within the cyanobacterial radiation and that prochlorophytes do not share a common ancestry with chlorophyll $a+b$-containing plastids to the exclusion of other cyanobacteria (Palenik and Haselkorn 1992, Urbach et al. 1992). The phylogenetic analyses of prochlorophyte sequences support multiple 
independent origins of chlorophyll $b$ within cyanobacteria (Palenik and Haselkorn 1992, Urbach et al. 1992; for the contrary view that the prochlorophytes are a monophyletic lineage that is evolutionarily distinct from cyanobacteria, see Larkum et al. 1994). The absence of cyanobacteria containing chlorophylls $a+b$ that are closely related to green algal/land plant plastids does not, however, preclude their former (and present) existence and their possible role in the origin of these plastids. Cyanobacteria that are most closely related to plastids in molecular sequence phylogenies (for exception, see later) contain chlorophyll $a$ and phycobilins (e.g. Synechococcus sp., Anabaena sp.) as in rhodoplasts and glaucocystophyte plastids (Palenik and Haselkorn 1992, Urbach et al. 1992, Delwiche et al. 1995, Helmchen et al. 1995); the glaucocystophyte plastids (cyanelles) also maintain the peptidoglycan wall of the putative cyanobacterial endosymbiont (Kies 1974, Kies and Kremer 1990, Helmchen et al. 1995).

The phylogenetic analyses that have most clearly supported a polyphyletic origin of plastids are based on comparisons of large and small subunits of ribulose-1,5-bisphosphate carboxylase/oxygenase (RUBISCO, $r b c \mathrm{~L}$ and $r b c \mathrm{~S}$ ) sequences. In these phylogenies, chlorarachniophyte, euglenophyte, green algal/land plant plastids, and the Cyanophora paradoxa cyanelle share a monophyletic origin and are rooted within the cyanobacteria, whereas the red algae, cryptophytes, and heterokonts are a closely related group that is rooted within proteobacteria (Douglas et al. 1990, Martin et al. 1992, Morden et al. 1992, McFadden et al., pers. commun.). Though initially interpreted as support for a polyphyletic origin of these plastids (Douglas et al. 1990, Valentin and Zetsche 1990a, b, Morden et al. 1992), the data can also be explained by a lateral transfer of the RUBISCO operon from a proteobacterium into the common ancestor of the red algae or, more likely, into the cyanobacterium that gave rise to the red algal plastid (Assali et al. 1990, Douglas et al. 1990, Martin et al. 1992, Loiseaux-de-Goer 1994); this plastid then presumably gave rise via secondary endosymbiosis(es) to the plastids of cryptophytes, heterokonts, and haptophytes (Gibbs 1981, 1993, Leipe et al. 1994, McFadden et al. 1994, and see later). Another explanation is the "differential retention of two RUBISCO operons present in the cyanobacterial ancestor of plastids"' (Douglas et al. 1990, Martin et al. 1992, quote from Palmer 1993).

Single origin of all plastids. In favor of the view that all extant plastids originated from a single primary endosymbiotic event (Cavalier-Smith 1982), the molecular phylogenies (except RUBISCO) presently show that all plastids share a monophyletic origin that is rooted within the cyanobacteria (Turner et al. 1989, Morden et al. 1992, Giovannoni et al. 1993, Douglas and Murphy 1994, Delwiche et al. 1995, Helmchen et al. 1995). Regardless of whether they are of a putative primary or secondary endosymbiotic origin, plastid gene content and gene order also argue for a shared common ancestry of these organelles (Kowallik 1993). Gene clusters such as those of atp $\mathrm{A}, p s a \mathrm{AB}, r p o \mathrm{BCD}$, and $r b c \mathrm{LS}$ and $\mathrm{ri}$ bosomal proteins are, for example, shared between cyanobacteria and the plastid of Cryptomonas $\phi$ (Douglas 1992). The plastids of red algae, heterokonts, and glaucocystophytes also share many operons in common with each other and with prokaryotes (Kowallik 1989, 1993, Palmer 1991, Douglas 1992, Löffelhardt and Bohnert 1994). The green algal/land plant plastids share fewer similarities in gene order and content with other plastids; chloroplasts have generally a smaller genome size because many more of the plastid genes have been transferred to the nucleus (Shivji et al. 1992, Kowallik 1993, Reith and Mulholland 1993). The presence of gene clusters that are shared by different plastid lineages but are absent from cyanobacteria argues most strongly for a monophyletic origin of all plastids (Douglas 1994). Barring extreme convergence, shared gene content and order in plastids from widely separated plant lineages is most easily explained by postendosymbiotic gene assembly in the single, common ancestor of these organelles (Douglas 1992, 1994, Kowallik 1993).

Given such a scenario, the present diversity of plastid pigmentation may be explained if the original cyanobacterial or cyanobacterial-like endosymbiont (which no longer exists or has yet to be found) contained chlorophylls $a+b+c+$ phycobilins. The initial photosynthetic eukaryote may, therefore, have contained components of more than one light-harvesting complex (LHC). The finding of a light-harvesting chlorophyll c-like pigment in Prochloron sp. supports this hypothesis (Larkum et al. 1994), as does the finding by Wolfe et al. (1994) of LHC polypeptides in red algae that are cross-reactive with polypeptides of the LHC of a land plant and a heterokont alga. These authors found that antibodies raised against polypeptides of the photosystem I complex of barley cross-react with components of the LHC I of the red algae, Aglaothamnion neglectum, and Porphyridium cruentum. Furthermore, components of the fucoxanthin-chlorophyll $a+c \mathrm{LHC}$ of the diatom Phaeodactylum tricomutum also cross-react with the red algal LHC I polypeptides. These data support a close evolutionary relationship among all plastids and are consistent with the hypothesis that the ancestral plastid contained both phycobilisomes and LHCs, and the loss of particular antenna systems may have resulted in the present array of diverse plastids (Bryant 1992, Douglas 1992, Wolfe et al. 1994). Further support for the existence of more than one light-harvesting antenna in the cyanobacterium that gave rise to all plastids is the finding of a chlorophyll $c-$-like pigment in prasinophyte green algae such as Mantoniella squamata (Wilhelm 1988). 
Prasinophytes, excluding the Chlorodendrales (sensu Melkonian 1990), form the earliest divergences in the green algal lineage (Steinkötter et al. 1994, Melkonian and Marin, unpubl. data).

Plastid rRNA phylogenies. The plastid-encoded ssu rRNA phylogenies show that there are at least two distinct plastid lineages (Douglas and Turner 1991, Morden et al. 1992, Giovannoni et al. 1993). The first is defined by the chlorophyll $a+b$-containing plastids of green algae/land plants, the second by the chlorophyll $a+$ phycobilin - containing plastids of rhodophytes, the chlorophyll $a+c$-containing plastids of heterokont and haptophyte algae, and the chlorophyll $a+c+$ phycobilin-containing plastids of the cryptophytes. The position of the chlorophyll $a+$ phycobilin-containing plastids of the glaucocystophytes is not stable within the ssu rRNA analyses; these sequences likely form a third distinct lineage (Douglas 1992, Helmchen et al. 1995). The chlorophyll $a+b$-containing plastids of the Euglenophyta appear to be most closely related to chloroplasts (Lockhart et al. 1992, 1994, Turner 1994, and see later).

Apart from the differences in plastid accessory pigment composition, there is also variation in the biochemistry of these organelles and the number of bounding membranes (Taylor 1976, Gibbs 1993). Plastids of the green algae/land plants, glaucocystophytes and red algae are surrounded by two envelope membranes-presumably the membranes of the engulfed cyanobacterium (Douce and Joyard 1981, Joyard et al. 1991). Two-membraned plastids (and the host cells that contain them) may share a monophyletic origin (kingdom Plantae; CavalierSmith 1982, 1993). Plastids that have more than two envelope membranes (e.g. three membranes, euglenophytes; three to four membranes, most dinofiagellates; four membranes, chlorarachniophytes/ cryptophytes/heterokonts/haptophytes, Dodge 1973, Gibbs 1981, 1993, Hibberd and Norris 1984, Schnepf 1993) may have arisen from the phagocytosis of a photosynthetic eukaryotic alga (secondary endosymbiosis; Gibbs 1981, Cavalier-Smith 1982, Douglas et al. 1991). The third membrane of these plastids is presumably the former plasmalemma of the engulfed eukaryote, whereas the fourth is the phagosomal membrane of the host cell (CavalierSmith 1982, for review see Whatley 1993a, b). In the cryptophytes, haptophytes, chlorarachniophytes, and heterokont algae, the phagosomal membrane is fused with the outer nuclear membrane to form the chloroplast endoplasmic reticulum (CER; Gibbs 1962, Whatley et al. 1979, Whatley 1993b). The distinct structure of the CER has been invoked as support for a monophyletic origin of these plastids via a single secondary endosymbiosis; the host cells that contain these four-membraned plastids have been postulated, therefore, to share also a monophyletic origin (Cavalier-Smith 1982, 1993).
Ribosomal RNA Phylogeny of

Photosynthetic Protists

Phylogenetic relationships between photosynthetic and nonphotosynthetic lineages within the "crown" group radiation (Knoll 1992, Wainright et al. 1993) are shown in Figure 1. The root of this maximum likelihood phylogeny lies within the branch leading to Dictyostelium discoideum. Figure 1 includes all major eukaryotic photosynthetic groups (shown in color) except for the Euglenophyta: euglenophytes diverge prior to $D$. discoideum and share a monophyletic origin with kinetoplastid protists (Sogin et al. 1986, Cavalier-Smith 1993, McFadden et al. 1994).

Evolutionary relationships among eukaryotes containing two-membraned plastids. The nuclear rRNA phylogeny shows that the three lineages that contain two-membraned plastids (i.e. chlorophytes, rhodophytes, and glaucocystophytes) have a polyphyletic origin within the crown group radiation (Fig. 1). The glaucocystophytes form a sister group to the cryptophytes, whereas the rhodophytes cluster with the cryptophyte/chlorarachniophyte nucleomorph sequences (Bhattacharya et al. 1995a); these groupings are not strongly supported by bootstrap analyses and are interpreted as provisional results. In particular, the positioning of the chlorarachniophyte nucleomorph sequences as a sister group to the cryptophyte nucleomorphs, which form a sister group to the red algae (not supported by the weighted parsimony analysis), may be the result of homoplasious branch "attraction" between these relatively highly divergent $r$ RNAs (Bhattacharya et al. 1995b). Though there is evidence to support a red algal ancestry of the cryptophyte nucleomorphs (Douglas et al. 1991, and see later), analysis of the plastid-encoded ssu rRNA within the chlorarachniophyte nucleomorph suggests that these protists are primitive green algae (McFadden et al., pers. commun.). The rRNA analyses clearly demonstrate, however, that the glaucocystophyte Glaucosphaera vacuolata is incorrectly classified and is a red alga (Helmchen et al. 1995). This result has important consequences because $G$. ilacuolata has been proposed as a "link" between rhodophytes and glaucocystophytes (i.e. within the Biliphyta, CavalierSmith 1982, 1993) because, for example, its plastid contains chlorophyll $a$ and phycobilins and is not bound by a peptidoglycan wall. In common, however, with the red algae, the $G$. inacuolata plastid contains R-phycocyanin (glaucocystophyte plastids contain C-phycocyanin, Kies and Kremer 1986), and its multiple "cyanelles" are most likely a single highly lobed rhodoplast (McCracken et al. 1980).

The rRNA analyses do not support a monophyletic origin of two-membraned plastids by demonstrating a monophyletic origin of the host cells (i.e. glaucocystophytes, red and green algae) that contain 

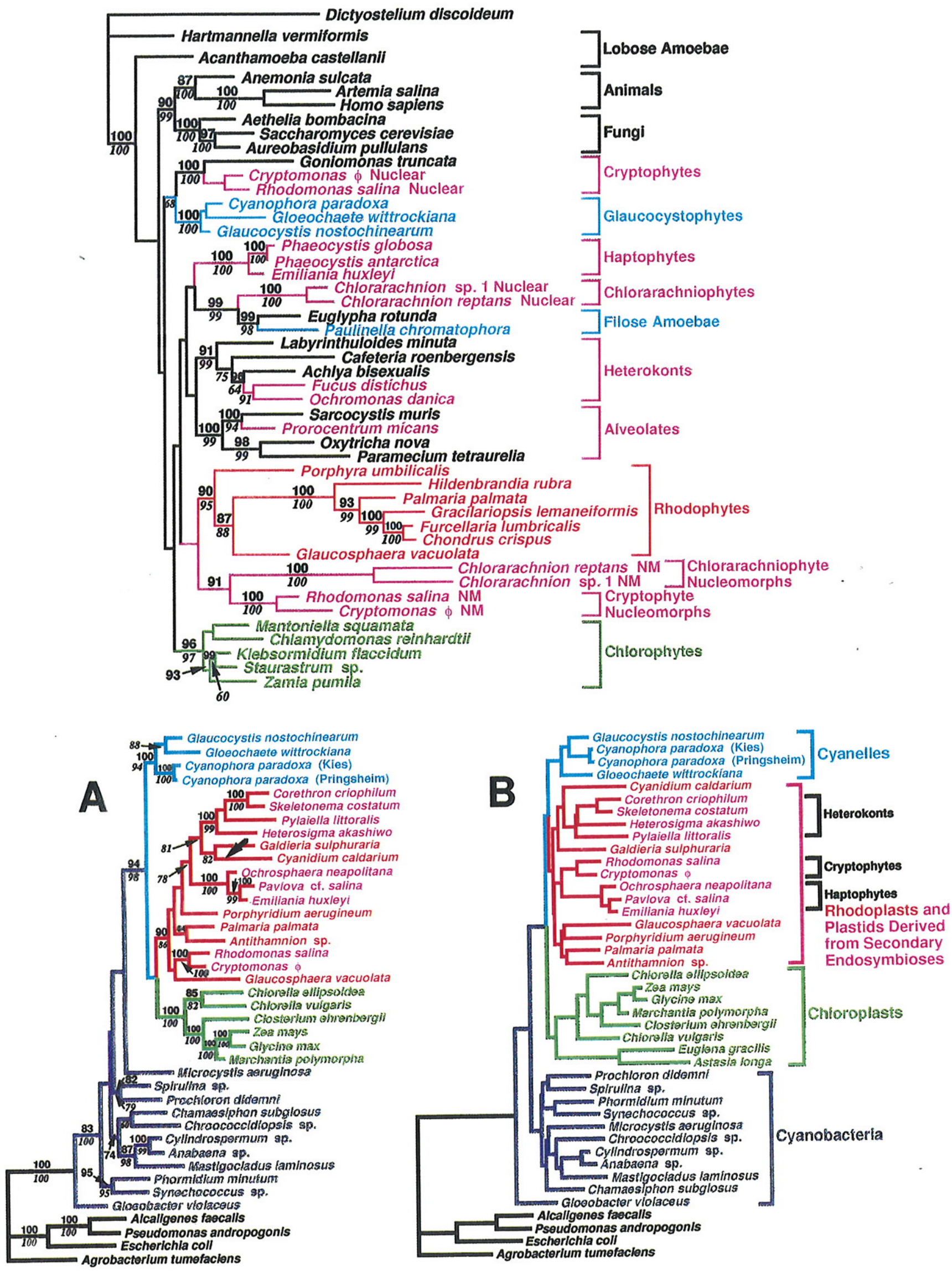
them. This resuit may be interpreted most easily in two ways. 1) The host cells share a monophyletic origin, but the shared common branch length uniting these taxa is too short to be resolved by rRNA sequence comparisons. This implies (as apparent in the analyses) a rapid radiation of the host cell lineages or a slow-down in sequence divergence at the time of the radiation (Leipe et al. 1994). A similar result is inferred from sequence comparisons of actin coding regions; these trees also demonstrate a near-simultaneous radiation of the crown group lineages (Bhattacharya et al. 1991, 1993). 2) The twomembraned plastids have independent primary endosymbiotic origins. Plastid gene sequence comparisons, gene content and order, and immunological relatedness of LHCs (see earlier) all suggest, however, that these organelles are closely related and likely share a monophyletic origin (Douglas 1992, Kowallik 1993, Douglas and Murphy 1994, Wolfe et al. 1994), which makes the second interpretation more unlikely. There is presently little evidence from biochemical, ultrastructural, or sequence studies to support a close evolutionary relationship among the host cells of chlorophytes, glaucocystophytes, and rhodophytes to the exclusion of other eukaryotic lineages (Zhou and Ragan 1993). All these groups (including the cryptophytes) do, however, contain flattened mitochondrial cristae and store starch as the reserve product in the cytoplasm; cryptophytes store starch in the periplastidial space outside their plastids (Gillott 1990).

In conclusion, the present data do not allow us to support or reject convincingly the hypothesis of a shared common ancestry of host cells containing two-membraned plastids. The great evolutionary distance that separates chlorophytes/rhodophytes/ glaucocystophytes/cryptophytes from each other may render testing their monophyly with nuclear gene sequence comparisons an untenable task. On the other hand, if mitochondrial cristae structure is a stable and reliable evolutionary marker, then this character supports the monophyly of these algae as well as the inclusion of the cryptophytes within this assemblage. Mitochondrial-encoded gene or complete organelle sequences may also provide markers that better resolve the evolutionary relationships of photosynthetic eukaryotes (Lang and Burger, pers. commun.).

Fic. 1. Phylogeny of eukaryotes based on ssu rRNA sequence comparisons inferred with the maximum likelihood method (fastDNAml, V1.0, Olsen et al. 1994) using 1612 unambiguously aligned nucleotides. The global search option was used with rearrangements of partial trees crossing one branch and rearrangements of the full tree crossing 44 branches. Taxon addition was jumbled and a transition /transversion ratio $=2$ was used. Figure 1 is rooted within the branch leading to Dictyostelium discoideum. The bootstrap values (100 replications) above the internal nodes are inferred from a distance analysis of the same data set using a Kimura (1980) matrix as input for a neishbor-joining phylogenetic reconstruction (Saitou and Nej 1987) with jumbled taxon addition and the transition/ transversion satio $=2$ (PHYL,IP, V3.5. Felsenstein 1993). The bootstrap values shown below the internal nodes in italic script are inferred from a weighted (rescaled consistency index over an interval of $1-1000$ ) maximum parsimony analysis (100 replications) for each site within the aligned data set; the maximum parsimony method is improved when sites that have relatively higher rates of change are given less weight in the phylogenetic analysis (Hillis et al. 1994). Only bootstrap values above $60 \%$ that define nodes shared by the maximum likelihood and the neighbor-joining or bootstrap consensus parsimony trees are recorded. In the bootstrapped parsimony analyses, data were used as input for a heuristic search with a branch-swapping algorithm (TBR, tree bisection-reconnection, PAUP, V3.1.1, Swofford 1993); chis consensus phylogram had a consistency index of 0.607 . Photosynthetic lineages in Figure 1 are shown in different colors; chloroplasts are shown in green, rhodoplasts in red, cyanelles in light blue, and plastids derived from putative secondary endosymbioses in purple. Arrows are used to indicate bootstrap values at nodes where these numbers do not fit on the branches. All sequences used in this analysis are available from the FMBL/Genbank or RDP database. Figure 1 has been redrawn from Bhattacharya et al. (1995).

Fig. 2. Evolutionary analyses of plastid-encoded ssu rRNAs. A) Phylogeny of $16 \mathrm{~S}$ rRNA sequences based on the comparison of 1403 unambiguously aligned nucleotide positions inferred with the maximum likelihood method (fastDNAml, Olsen et al. 1994) using empirically determined base frequencies. The global search option was used with rearrangements of partial trees crossing 1 branch and rearrangements of the full tree crossing 37 branches. Results of a bootstrap analysis (100 replications, Felsenstein 1985) with the neighbor-joining method are shown above the internal nodes in Figure $2 \mathrm{~A}$, whereas the bootstrap values shown below the internal nodes in italic script are inferred from a weighted (rescaled consistency index over an interval of $\mathrm{I}-1000$ ) maximum parsimony analysis ( 100 replications). Only bootstrap values above $60 \%$ that define nodes shared by the maximum likelihood and the neighbor-joining or maximum parsimony bootstrap consensus trees are recorded. In the bootstrapped maximum parsimony analysis, random additions of the weighted data were analyzed with a heuristic search method with a branch-swapping algorithm (TBR, tree bisection-reconnection, PAUP, V3.1.1, Swofford 1993); this consensus phylogram had a consistency index of 0.597. Both maximum likelihood and neighborjoining phylogenetic methods used a jumbled species input and a transition/transversion ratio of 2 and were rooted on the branch length leading to the Agrobacterium tumefaciens $16 \mathrm{~S}$ rRNA sequence. The large arrow on the branch leading to Cyanidium caldarium indicates the divergence point of the rRNA sequences of Euglena gracilis and Astasia longa (Euglenophyta) when these are included in the phylogenetic analyses. The smaller arrows are used to indicate bootstrap values at nodes where these numbers do not fit on the branches. B) Phylogeny inferred with the neighbor-joining method (Saitou and Nei 1987) using a LogDet matrix (Lockhart et al. 1994) as input. Only parsimony sites (512 nt) were included in the Log Det analysis; gaps were excluded. Plastid lineages are shown in different colors; chloroplasts are shown in green, rhodoplasts in red, cyanelles in light blue, cyanobacteria (including prochlorophytes) in dark blue, and plastids derived from putative secondary endosymbioses in purple, except for the euglenophyte plastids (Fig. 2B), which are shown in green. All $16 \mathrm{~S}$ rRNA sequences used in this analysis except those of Corethron criophilum, Emiliania huxleyi, Skeletonema costalum (Medlin, unpubl. data), Closterium ehrenbergii (Kim et al. 1994), Cyanidium caldarium (Giovannoni, unpubl. data), Chroococcidiopsis sp. (Turner, unpubl. data), and Porphyridium aerugineum (Maid and Zetsche, unpubl. data) are available from the EMBL/Genbank or RDP database. 
It should be noted that if chlorophytes/rhodophytes/glaucocystophytes/cryptophytes share a monophyletic origin, then the cryptophytes may initially have been cyanelle-bearing protists that retained their phagocytotic capacity; the cyanelle would have been subsequently lost and replaced by the secondary endosymbiosis of a eukaryotic alga. Cyanelle-containing cryptomonads may still exist (e.g. Peliaina cyanea, Bourrelly 1970).

Evolutionary relationships among eukaryotes containing three-/or four-membraned plastids. In contrast to the chlorophytes, rhodophytes, and glaucocystophytes, which arise as plastid-bearing lineages from the radiation (based on the available data), the euglenophytes, cryptophytes, chlorarachniophytes, dinophytes, and heterokonts have aplastidial taxa as sister groups or early divergences (e.g. Goniomonas iruncata, Cryptophyta [McFadden et al. 1994], Labyrinthuloides minuta, Heterokonta [Leipe et al. 1994]). These latter lineages, which all contain threeor four-membraned plastids, do not share a close evolutionary relationship (Bhattacharya et al. 1992) and appear to have gained their plastids secondarily and independently from each other (Gibbs 1993, Whatley $1993 \mathrm{a}, \mathrm{b}$ ); this scheme does not conflict with a putative cyanelle-containing ancestor to cryptophytes. The topology shown in Figure 1 is not consistent with a monophyletic origin of host cells containing four-membraned plastids with associated CER (Cavalier-Smith 1982, 1993, Cavalier-Smith et al. 1994).

As an example, the close evolutionary relationship between the chlorarachniophytes and the filose amoebae (Euglyphidae/Paulinellidae) strongly suggests that the common ancestor of these taxa was nonphotosynthetic and that the chlororachniophytes gained their plastid from a eukaryotic alga, whereas Paulinella chromatophora gained its cyanelle either from an independent cyanobacterial endosymbiosis or from the secondary endosymbiosis of a glaucocystophyte (Bhattacharya et al. 1995b). It is conceivable that the common ancestor of this assemblage contained a cyanelle, which was lost in the chlorarachniophytes and all filose amoebae (except Paulinella); the cyanelle would have been replaced by the plastid of a eukaryotic alga in the chlorarachniophytes. There exists, however, no evidence for a cyanelle-bearing ancestor to the Euglyphidae/ Paulinellidae/Chlorarachniophyta (i.e. no other cyanelle-bearing filose amoeba [or chlorarachniophytes] are known), whereas there is evidence for a heterotrophic ancestry for $P$. chromatophora in the closely related nonphotosynthetic Paulinella ovalis (Johnson et al. 1988). Apart from some differences in scale shape and cell size, $P$. ovalis is morphologically identical to $P$. chromatophora but lacks cyanelles or any vestige of a photosynthetic organelle. Electron microscopic analyses show that $P$. oralis regularly ingests cyanobacteria as a food source; the cy- anobacteria are localized within food vacuoles in the cell (Johnson et al. 1988).

Ribosomal RNA Phylogeny of Plastids

Cyanobacterial origin of all plastids. Apart from providing strong evidence for a close evolutionary relationship among all plastids (94 and $98 \%$ bootstrap support in the neighbor-joining and maximum parsimony analyses, respectively), the phylogenetic analyses position the plastid lineage as a sister group to the cyanobacteria (Fig. 2A). Usage of a phylogenetic method that corrects for biased base composition ( LogDet transformation, Lockhart et al. 1994) also positions the cyanobacteria as an evolutionarily distinct lineage that is a sister group to the plastids (Fig. 2B, and see later). Inclusion of $11 \mathrm{com}-$ plete (or nearly complete) cyanobacterial ssu rRNA sequences in the analyses representing the five sections described by Rippka et al. (1979) and the prochlorophytes (i.e. Prochloron didemni) shows that these taxa form a monophyletic lineage (except for Gloeobacter violaceus) that is evolutionarily distinct from the plastids. The positioning of $G$. violaceus at the base of the cyanobacteria/plastids suggests that this peculiar cyanobacterium, which lacks intracellular photosynthetic thylakoids (Rippka et al. 1974), is a sister group to all photosynthetic organisms (Wilmotte et al. 1992). Inclusion of partial ssu rRNA sequences from other cyanobacterial taxa (e.g. Oscillatoria williamsii, Plectonema boryanum, Prochlorococcus marinus, Prochlorothrix hollandica) in the phylogenetic analyses did not alter the divergence point of $G$. violaceus, the monophyletic origin of the other cyanobacteria, and the monophyletic origin of the plastids. Usage of partial (e.g. $1009 \mathrm{nt}$ ) ssu rRNA sequences did, however, generally reduce the bootstrap support for monophyletic groups in both cyanobacterial and plastid lineages and lead to minor topological rearrangements such as the positioning of the cyanelles as the first plastid divergence in the maximum parsimony analysis (Bhattacharya and Medlin, unpubl. data).

Two-membraned plastids. Maximum likelihood analyses of ssu rRNAs suggest that two-membraned plastids form three distinct lineages (Fig. 2A), which diverge nearly simultaneously from each other (Bhattacharya et al. 1995a, Helmchen et al. 1995). This analysis positions the glaucocystophyte plastids as the first divergence followed closely by the divergence of chlorophyte and rhodophyte plastids. The red algal plastids have a paraphyletic origin within the lineage defined by these and the fourmembraned plastids (Medlin et al. 1994). Cyanidium caldarium and Galdieria sulphuraria form a cluster distinct from that defined by the other rhodoplasts (i.e. Antithamnion sp., Glaucosphaera vacuolata, Palmaria palmata, Porphyridium aerugineum).

In contrast to the maximum likelihood analysis, the neighbor-joining and maximum parsimony anal- 
yses suggest that the glaucocystophyte plastids are more closely related to rhodoplasts than to chloroplasts (Helmchen et al. 1995). To address this issue, the likelihoods of user-defined trees that position the cyanelles with either the chloroplasts or the rhodoplasts have been calculated. Comparison of the likelihoods of these trees with the "best" tree (i.e. cyanelles as the earliest divergence) with the likelihood ratio test of $\mathrm{Kishino}$ and Hasegawa (1989) has shown that the positioning of the cyanelles with either the chloroplasts or rhodoplasts does not result in a significantly "worse" phylogeny than that shown in Figure 2A (Helmchen et al. 1995). These data support a near-simultaneous radiation of cyanelles and red and green plastids. If the maximum likelihood analysis most accurately reflects the evolutionary relationships among these plastid types, then the peptidoglycan wall surrounding the cyanelle was lost once in evolution after the divergence of the glaucocystophytes. The user-defined tree analyses show conclusively, however, that the positioning of the Glaucosphaera vacuolata plastid with the cyanelles is not favored in the maximum likelihood analysis (Helmchen et al. 1995). This latter result is consistent with the host cell phylogeny shown in Figure 1.

Four-membraned plastids. The topological relationships among plastids with four envelope membranes are shown in Figure $2 \mathrm{~A}$. These plastids share a monophyletic origin with rhodoplasts and are evolutionarily distinct from chloroplasts and cyanelles. The plastid phylogeny may be interpreted as supporting the origin of the four-membraned plastids of the cryptophytes, heterokonts, and haptophytes from the secondary endosymbioses of a precursor to the red algae; a "red algal" origin of the cryptophyte plastid has been previously suggested on the basis of a close evolutionary relationship between the host cell ssu rRNAs of the cryptophyte nucleomorphs and the red algae (Douglas et al. 1991). The maximum likelihood and maximum parsimony analyses show, for example, a close evolutionary relationship between the rhodoplasts of Cyanidium caldarium and Galdieria sulphuraria and the heterokont plastids (Fig. 2A). As further support for the ancestral position of rhodoplasts within the phylogeny of four-membraned plastids, the $r b c \mathrm{~L}$ amino acid sequences of $C$. caldarium and Antithamnion sp. are positioned with high bootstrap support at the base of the haptophyte, cryptophyte, and heterokont plastid divergences (Fujiwara et al. 1993). Phylogenies inferred from other plastid protein sequences also demonstrate a close evolutionary relationship between rhodoplasts and plastids with four bounding-membranes (e.g. psbA, tufA, Morden et al. 1992, Delwiche et al. 1995; atp B, Douglas and Murphy 1994).

There are, however, only a small number of plastid characters that support a close evolutionary relationship between rhodoplasts and four-mem- braned plastids. These include the linkage of both subunits of RUBISCO (presumably the ancestral state for all plastids) in the plastid of these taxa (Fujiwara et al. 1993, Loiseaux-de-Goer 1994), whereas $r b c S$ is nuclear-encoded in the green algae/land plants (Douglas 1992). Also, plastocyanin is not used as the final electron transfer molecule to the P700 complex in these algae and the Euglenophyta (J.A. Raven 1987). Interestingly, except for the cryptomonads, algae with four-membraned plastids and the Euglenophyta store their reserve photosynthate as a $\beta-1-3$-glucan outside the plastid (Whatley and Whatley 1981). The unique characters that define cryptophyte and haptophyte/heterokont plastids (Dodge 1973, Engel et al. 1993, Whatley 1993a) suggest that, though evolutionarily related to each other, these organelles may not be traced to a single eukaryote as the source of the secondary endosymbiosis.

Euglenophyte plastids. The positioning of the euglenophyte host cells as an early divergence within the ssu rRNA phylogenies, surrounded by many nonphotosynthetic protists, strongly supports an independent secondary endosymbiotic origin of the plastid of these flagellates. Characters shared by euglenophyte plastids and chloroplasts (i.e. chlorophylls $a+b$, chloroplast gene arrangement; Hallick et al. 1993) suggests that a green alga was the source of this plastid. Phylogenetic analyses of the plastid $16 \mathrm{~S}$ rRNA from euglenophytes have, however, positioned these sequences among the rhodoplasts (see Fig. 2A, Douglas and Turner 1991, Giovannoni et al. 1993). Reanalyses of these data with the LogDet method shows that the grouping of euglenophyte and red algal plastids in $16 \mathrm{~S} r \mathrm{RNA}$ trees likely reflects the nucleotide composition of these sequences rather than their evolutionary history (Fig. 2B, Howe et al. 1992, Lockhart et al. 1994, Turner 1994, Helmchen et al. 1995). Plastid protein phylogenies, for example, support a green algal ancestry of the euglenophyte plastid (Morden et al. 1992). That euglenophytes store $\beta-1-3$-glucans outside their plastids like haptophytes and heterokonts (and not starch

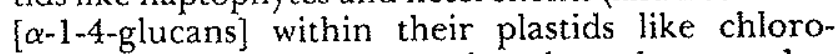
phytes) suggests, however, that the eukaryote that gave rise to these plastids was not an evolutionarily derived chlorophyte. The positioning of the euglenophyte plastids as the earliest divergence within the chloroplast lineage in Figure 2B supports this hypothesis. Other biochemical evidence that allies plastids of the Euglenophyta with those of heterokont algae, to the exclusion of the green algal/land plant plastids, are 1) high ratios of chlorophylls $a: b$ $(>2.5), 2)$ the absence of violaxanthin and lutein, 3) the presence of acetylinic carotenoids, 4) the absence of plastocyanin, and 5) the ability to assimilate sulfate and nitrate (see review in J. A. Raven 1987). Additional evidence showing the distinct nature of the Euglena plastid comes, in contrast to other plas- 
tids, from the large number of introns encoded by this genome (i.e. $38.3 \%$ introns in E. gracilis, Hallick et al. 1993).

\section{Conclusions and Prospects}

The analyses and interpretations of data regarding plastid endosymbioses presented here lead to two main conclusions. 1) There was a single primary endosymbiotic event in which a cyanobacterium gave rise to all extant plastids (Cavalier-Smith 1982), presently excluding the Paulinella chromatophora cyanelle. This conclusion is supported by the phylogenetic analyses of eubacterial (including cyanobacterial) and plastid ssu rRNAs presented in Figure $2 \mathrm{~A}, \mathrm{~B}$, and by the close evolutionary relationship between plastids and cyanobacteria shown in the analyses of tufA sequences from plastids and diverse eubacterial taxa (Delwiche et al. 1995). 2) There were multiple, likely independent secondary endosymbioses that gave rise to the plastids of chlorarachniophytes, cryptophytes, euglenophytes, haptophytes, and heterokonts. In support of the scenario that secondary endosymbioses may have occurred relatively frequently in evolution, as suggested by the evolutionary relationships among eukaryotes containing plastids with more than two envelope membranes shown in Figure 1, is the existence of the varied plastids of the dinoflagellates and the regular renewal of photosynthetic organelles within vacuoles by protozoa (Laval-Peuto 1992). There are presently no rRNA data of dinoflagellate plastids. There exists, however, well-documented ultrastructural evidence for secondary endosymbiotic origins of plastids for dinoflagellate taxa (e.g. three membranes; Dodge 1989, Schnepf 1993). In addition, some of these putative secondary endosymbionts can be attributed to different algal lineages based on pigment or ultrastructure data (e.g. prasinophytes [in Lepidodinium viride, Watanabe et al. 1991], cryptophytes [in Dinophysis sp., Schnepf and Elbrächter 1988], haptophytes [in Gyrodinium aureolum, Tangen and Björnland 1981], heterokonts [in Glenodinium foliaceum, Schnepf 1993]). If the dinoflagellate plastids are of a polyphyletic origin, then they may be traced to the lineage that gave rise to all plastids (i.e. contained chlorophylls $a+b+c$ and phycobilins) or from its descendants (e.g. prasinophytes). The molecular evolutionary analysis of diverse dinoflagellate plastids promises to provide the last major evidence regarding the origins of these organelles.

We thank M. Melkonian for fruitful discussions about glaucocystophytes and other algae, P. K. Hayes for discussions about cyanobacteria, T. Helmchen for his efforts in the lab, S. Giovannoni, V. A. R. Huss, U. Maid, S. Turner, and K. Zetsche for kindly providing access to unpublished ssu rRNA sequences, $S$. Turner for many helpful comments, and two reviewers for their critical reading of this manuscript. This work was supported by a grant from the Deutsche Forschungsgemeinschaft (ME 658) $11-2)$ to M.M. and D.B. and from the Deutsche Forschungsge- meinschaft (Sm 22/7-1), the NERC (GST/02/223) and the EC (MAST-PL92.0058) to L.M. This is contribution 854 from the Affred-Wegener-Institute and contribution 46 from EHUX.

Assali, N. E., Mache, R. \& Loiseaux-de-Goer, S. 1990. Evidence for a composite phylogenetic origin of the plastid genome of the brown alga Pylaiella littoralis (L) Kjellm. Plant Mol. Biol. 15:307-15.

Bhattacharya, D., Helmchen, T., Bibeau, C. \& Melkonian, M. 1995a. Comparisons of small subunit ribosomal RNAs reveal the evolutionary position of the Glaucocystophyta. Mol. Biol. Evol. 12:415-20.

Bhattacharya, D., Helmchen, T. \& Melkonian, M. 1995b. Molecular evolutionary analyses of nuclear-encoded small sub. unit ribosomal RNA identify an independent rhizopod lineage containing the Euglyphidae and the Chlorarachniophyta. J. Euk. Microbiol. 42:65-9.

Bhattacharya, D., Medlin, L., Wainright, P. O., Ariztia, E. V., Bibeau, C., Stickel, S. K. \& Sogin, M. L. 1992. Algae containing chlorophylls $a+c$ are polyphyletic: molecular evolu. tionary analysis of the Chromophyta. Evolution 46:1801-17.

Bhattacharya, D., Stickel, S. K. \& Sogin, M. L. 1991. Molecular phylogenetic analysis of actin genic regions from Achlya bisexualis (Oomycota) and Costaria costata (Chromophyta). J. Mol. Evol. 33:525-36.

Bhattacharya, D., Stickel, S. K. \& Sogin, M. L. 1993, Isolation and molecular phylogenetic analysis of actin coding regions from the prymnesiophyte alga, Emiliania huxleyi, using reverse transcriptase and PCR methods. Mol. Biol. Evol. 10: 689-703.

Bourrelly, P. 1970. Les algues d'eau douce. Tome III: Les algues bleus et rouges. Les eugleniens, peridiniens et cryptomonadiniens. N. Boubée and Cie, Paris, 512 pp.

Bryant, D. A. 1992. Puzzles of chloroplast ancestry. Curr. Biol. $2: 240-2$.

Cavalier-Smith, T. 1982. The origins of plastids. Biol. J. Linn Soc. 17:289-306.

1993. Kingdom Protozoa and its 18 phyla. Microbiol. Rev. $57: 953-94$

Cavalier-Smith, T., Allsopp, M. 'T. E. P. \& Chai, E. E. 1994. Chimeric conundra: are nucleomorphs and chromists monophyletic or polyphyletic? Proc. Nat. Acad. Sci. U.S.A. 91:1136872 .

Delwiche, C. F., Kuhsel, M. \& Palmer, J. D. 1995. Phylogenetic analysis of tufA sequences indicates a cyanobacterial origin of all plastids. Mol. Phyl. Evol. (in press).

Dodge, J. D. 1973. The Fine Siructure of the Algae. Academic Press, London, $26 \mathrm{I} \mathrm{pp.}$

1989. Phylogenetic relation of dinoflagellates and their plastids. In Green, J. C., Leadbeater, B. S. C. \& Diver, W. L. [Eds.] The Chromophyte Algae: Problems and Perspectives. Systematics Association Special Volume 38. Clarendon Press, Oxford, pp. 207-27.

Douce, R. \& Joyard, J. 198I. Does the plastid envelope derive from the endoplasmic reticulum. Trends Biochem. Sci. 6:237-9.

Douglas, S. E. 1992. Eukaryote-eukaryote endosymbioses: insights from studies of a cryptomonad alga. BioSystems 28:5768 .

- 1994. Chloroplast origins and evolution. In Bryant, D. A. [Ed.] The Molecular Biology of the Cyanobacteria. Kluwer Academic Publishers, Dordrecht, pp. 91-118.

Douglas, S. E., Durnford, D. G. \& Morden, C. W. 1990. Nucleotide sequence of the gene for the large subunit of ribulose1,5-bisphosphate carboxylase/oxygenase from Cryptomonas $\phi$ : evidence supporting the polyphyletic origin of plastids. $J$ Phycol. 26:500-8.

Douglas, S. E. \& Murphy, C. A. 1994. Structural, transcriptional and phylogenetic analyses of the $a t p B$ gene cluster from the plastid of Cryptomonas $\phi$ (Cryptophyceae). J. Phycol. 30:32940 .

Douglas, S. E., Murphy, C. A., Spencer, D. F. \& Gray, M. W. 1991. Cryptomonad algae are evolutionary chimeras of two 
phylogenetically distinct unicellular eukaryotes. Nature (Lond.) 350:148-51.

Douglas, S. E. \& Turner, S. 1991. Molecular evidence for the origin of plastids from a cyanobacterium-like ancestor. $J$. Mol. Erol. 33:267-73.

Engel, E., Boggasch, E. \& Huss, V. A. R. 1993. The unusual size of the plastome of some prymnesiophytes: new aspects in plastid evolution. Abstract. The Biology of the Prymnesiophyta. Plymouth, U.K.

Felsenstein, J. 1985. Confidence limits on phylogenies: an approach using the bootstrap. Evolution 39:783-91.

proach 1993. PHYLIP Manual, Version 3.5. Department of Genetics, University of Washington, Seattle.

Fujiwara, S., Iwahashi, H., Someya, J. \& Nishikawa, S. 1993. Structure and cotranscription of the plastid-encoded $r b c \mathrm{~L}$ and $r b c S$ genes of Pleurochrysis carterae (Prymnesiophyta). $J$. Phycol. 29:347-55.

Gibbs, S. 1962. Nuclear enveiope-chloroplast relationships in algae. J. Cell Biol. 14:433-44.

1981. The chloroplasts of some algal groups may have evolved from endosymbiotic eukaryotic algae. Ann. N.Y. Acad. Sci. 361:193-207.

_ 1993. The evolution of algal chloroplasts. In Lewin, R. A. [Ed.] Origins of Plastids. Chapman and Hal\}, New York, pp. $107-21$.

Gillott, M. 1990. Phylum Cryptophyta. In Margulis, L., Corliss, J. O., Melkonian, M. \& Chapman, D. J. [Eds.\} Handbook of Protoctista. Jones and Bartlett Publishers, Boston, pp. 13951.

Giovannoni, S. J., Turner, S., Olsen, G. J., Barns, S., Lane, D. J. \& Pace, N. R. 1988. Evolutionary relationships among cyanobacteria and green chloroplasts. $J$. Bacteriol. 170:358492.

Giovannoni, S. J., Wood, N. \& Huss, V. 1993. Molecular phylogeny of oxygenic cells and organelles based on smali-subunit ribosomal RNA sequences. In Lewin, R. A. [Ed.] Origins of Plastids. Chapman and Hall, New York, pp. 159-70.

Hallick, R. B., Hong, L., Drager, R. G., Favreau, M. R., Monfort, A., Orsat, B., Spielmann, A. \& Stutz, F. 1993. Complete sequence of Euglena gracilis chloroplast DNA. Nucl. Acids Res. $21: 3537-44$.

Helmchen, T., Bhattacharya, D. \& Meikonian, M. 1995. Analm yses of ribosomal RNA sequences from glaucocystophyte cyanelles provide new insights into the evolutionary relationships of plastids. J. Mol. Evol. (in press).

Hibberd, D. J. \& Norris, R. E. 1984. Cytology and ultrastructure of Chlorarachnion reptans (Chlorarachniophyta divisio nova, Chlorarachniophyceae classis nova). J. Phycol. 20:310-30.

Hillis, D. M., Huelsenbeck, J. P. \& Swofford, D. 1994. Hobgoblin of phylogenetics. Nature (Lond.) 369:363-4.

Howe, C. J., Beanland, T. J., Larkum, A. W. D. \& Lockhart, P. J. 1992. Plastid phylogeny and the problem of biased base composition. In Lewin, R. A. [Ed.] Origins of Plastids. Chapman and Hail, New York, pp. 349-53.

Johnson, P. W., Hargraves, P. E. \& Sieburth, J. McN. 1988 Ultrastructure and ecology of Calycomonas ovalis Wulf, 1919, (Chrysophyceae) and its redescription as a testate rhizopod, Paulinella ovalis N. Comb. (Filosea: Euglyphina). J. Protozaol. $35: 618-26$.

Joyard, J., Block, M. A. \& Douce, R. 1991. Molecular aspects of plastid envelope biochemistry. Eur.J. Biochem. 199:489-509.

Kies, L. 1974. Elektronenmikroskopische Untersuchungen an Paulinella chromatohora Lauterborn, einer Thekamöbe mit blaugrünen Endosymbionten (Cyanellen). Protoplasma 80:6989.

Kies, L. \& Kremer, B. P. 1986. Typification of the Glaucocystophyta. Taxon 35:128-33.

Kies, L. \& Kremer, B. P. 1990. Phylum Glaucocystophyta. In Margulis, L., Corliss, J. O., Melkonian, M. \& Chapman, D. J. [Eds.] Handbook of Protoctista. Jones and Bartlett Publishers, Bostun, pp. 152-16.

Kim, Y-S., Oyaizu, H., Matsumoto, S., Watanabe, M. M. \& Nozaki, H. 1994. Chloroplast small-subunit ribosomal RNA gene sequence from Chlamydomonas parkeae (Chlorophyta): molecujar phylogeny of a green alga with a peculiar pigment composition. Eur. J. Phycol. 29:213-7.

Kimura, M. 1980. A simple method for estimating evolutionary rates of base substitution through comparative studies of sequence evolution. J. Mol. E:ol. 16:111-20.

Kishino, H. \& Hasegawa, M. 1989. Evaluation of the maximum likelihood estimate of the evolutionary tree topologies from DNA sequence data, and the branching order of the Hominoidea. J. Mol. Evol. 29:170-9.

Knoll, A. H. 1992. The early evolution of eukaryotes: a geological perspective. Science (Wash. D.C.) 256:622-7.

Kowallik, K. V. 1989. Molecular aspects and phylogenetic implications of plastid genomes of certain chromophytes. In Green, J. C., Leadbeater, B. S. C. \& Diver, W. L. [Eds.] The Chromophyte Algae: Problems and Perspectives. Clarendon Press, Oxford, pp. 101-24.

1993. Origin and evolution of plastids from chiorophyll$a+c-$ containing algae: suggested ancestral relationships to red and green algal plastids. In Lewin, R. A. [Ed.] Origins of Plastids. Chapman and Hall, New York, pp. 223-63.

Larkum, A. W. D., Scaramuzzi, C., Cox, G. C., Hiller, R. G. \& Turner, A. G. 1994. Light-harvesting chlorophyll $c$-like pigment in Prochloron. Proc. Nat. Acad. Sci. U.S.A. 91:679-83.

Laval-Peuto, M. 1992. Plastidic protozoa. In Reisser, N. [Ed.] Algae and Symbioses. Biopress, Bristol, pp. 471-99.

Leipe, D. D., Wainwright, P. O., Gunderson, J. H., Porter, D., Patterson, D. J., Valois, F., Himmerich, S. \& Sogin, M. L. 1994. The stramenopiles from a molecular perspective: $16 \mathrm{~S}$ like rRNA sequences from Labyrinthuloides minuta and Cafeteria roenbergensis. Phycologia 33:369-77.

Lewin, R. A. 1976. Prochlorophyta as a proposed new division of algae. Nature (Lond.) 261:697-8.

1993. Origins of Plastids. Chapman and Hall, London, 393 pp.

Lockhart, P. J., Howe, C. J., Bryant, D. A., Beanland, T. J. \& Larkum, A. W. D. 1992. Substitutional bias confounds inference of cyanelle origins from sequence data. J. Mol. Evol. $34: 153-62$

Lockhart, P. J., Steel, M. A., Hendy, M. D. \& Penny, D. 1994. Recovering evolutionary trees under a more realistic model of sequence evolution. Mol. Biol. Evol. 11:605-12.

Löffelhardt, W. \& Bohnert, H. J. 1994. Molecular biology of cyanelies. In Bryant, D. A. [Ed.] The Molecular Biology of the Cyanobacteria. Kluwer, Dordrecht, pp. 65-89.

Loiseaux-de-Goer, S. 1994. Plastid lineages. Prog. Phycol. Res. 10: (in press).

Maidak, B. L., Larsen, N., McCaughey, M. J., Overbeek, R., Olsen, G. J., Fogel, K., Blandy, J.\&. Woese, C. R. 1994. The ribosomal database project. Nucl. Acids Res. 22:3485 7.

Margulis, L. 1981. Symbiosis in Cell Eiolution. Freeman, Chicago, 419 pp.

Martin, W., Somerville, C. C. \& Loiseaux-de Goer, S. 1992. Molecular phylogenies of plastid origins and algal evolution. $J$. Mol. Evol. 35:385-404.

McCracken, D. A., Nadakavukaren, M. J. \& Cain, J. R. 1980. A biochemical and ultrastructural evaluation of the taxonomic position of Glaucosphaera vacuolata Korsh. New Phytol. 86:3944.

McFadden, G, 1., Gilson, P. R. \& Hill, D. R. A. 1994. Goniomonas-rRNA sequences indicate that this phagotrophic flageliate is a close relative of the host component of cryptomonads. Eur. J. Phycol. 29:29-32.

Medlin, L. K., Barker, G. L. A., Baumann, M., Hayes, P. K. \& Lange, M. 1994. Molecular biology and systematics. In Green, J. C. \& Leadbeater, B. S. C. [Eds.] The Haptophyte Algae. Systematics Association Special Publication, Oxford University Press, Clarendon, pp. 393-411.

Melkoniaı, M. 1990. Phylum Chlorophyta: class Prasinophyceae. In Margulis, L., Corliss, J. O., Melkonian, M. \&c Chapman, D. J. [Eds.] Handbook of Protoctista. Jones and Bartiett Publishers, Boston, pp. 600-7. 
Mereschkowsky, C. 1905. Uber Natur und Ursprung der Chromatophoren im Pflanzenreiche. Biol. Zentralbl. 25:593-604. - 1910. Theorien der zwei Plasmaarten als Grundlage der Symbiogenesis, einer neuen Lehre der Entstehung der Organismen. Biol. Zentralbl. 30:278-303.

Morden, C. W., Delwiche, C. F, Kuhsel, M. \& Palmer, J. D. 1992. Gene phylogenies and the endosymbiotic origin of plastids. BioSystems 28:75-90.

Olsen, G. J., Matsuda, H., Hagstrom, R. \& Overbeek, R. 1994. fastDNAml: a tool for construction of phylogenetic trees of DNA sequences using maximum likelihood. CABIOS 10:41-8.

Palenik, B. \& Haselkorn, R. 1992. Multiple evolutionary origins of prochlorophytes, the chlorophyll $b$-containing prokaryotes. Valure (Lond.) 355:265-7.

Palmer, J. D. 1991. Plastid chromosomes: structure and evolution. In Bogorad, L. \& Vasil, I. K. [Eds.] The Molecular Biology of Plastids. Cell Culture and Somatic Cell Genetics of Plants, Vol. 7A. Academic Press, New York, pp. 5 53.

1993. A genetic rainbow of plastids. Nalure (Lond.) 364 : $762-3$.

Raven, J. A. 1987. Biochemistry, biophysics and physiology of chlorophyll $b-$ containing algae; implications for taxonomy and phylogeny. In Round, F. E. \& Chapman, D. J. [Eds.] Progress in Phycological Research, Vol. 5. Biopress, Bristol, pp. $1-122$.

Raven, P. H. 1970. A multiple origin of plastids and mitochondria. Science (Wash. D.C.) 169:641-6.

Reith, M. \& Mulholland, J. 1993. A high resolution gene map of the chloroplast genome of the red alga Porphyra purpurea. Plant Cell 5:465-75.

Rippka, R., Deruelles, J., Waterbury, J. B., Herdman, M. \& Stanier, R. X. 1979. Generic assignments, strain histories and properties of pure cultures of cyanobacteria. J. Gen. Microbiol. $111: 1-61$.

Rippka, R., Waterbury, J. B. \& Cohen-Bazire, G. 1974. A cyanobacterium which lacks thylakoids. Arch. Wicrobiol. 100:41936 .

Saitou, N. \& Nei, M. 1987. The neighbor-joining method: a new method for reconstructing phylogenetic trees. Mol. Biol. Evol $4: 406-25$.

Schimper, A. F. W. 1883. Über die Entwicklung der Chlorophyllkörner und farbkörner. Bot. Zeit. 41:105-14.

Schnepf, E. 1993. From prey via endosymbiont to plastid: com. parative studies in dinoflagellates. In Lewin, R. A. [Ed.] Origins of Plastids. Chapman and Hall, New York, pp. 53-76.

Schnepf, E. \& Elbrächter, M. 1988. Cryptophycean-like doublemembrane bounded chloroplast in the dinoflagellate, Dinophysis Ehrenb. evolutionary, phylogenetic and toxicological implications. Bol. Acto 101:196-203.

Shivji, M. S., Li, N. \& Cattolico, R. A. 1992. Structure and organization of rhodophyte and chromophyte plastid genomes: implications for the ancestry of plastids. Mol. Gen. Genet. 232:65-75.

Sogin, M. L. 1991. The phylogenetic significance of sequence diversity and length variations in eukaryotic small subunit ribosomal R.it coding regions. Wistar Symp. Ser. 4:175-88.

Sogin, M. L., Elwood, H. J. \& Gunderson, J. H. 1986. Fvolutionary diversity of eukaryotic small-subunit rRNA genes. Proc. Nat. Aead. Sci. U.S.A. 83:1383-7.

Steinkötter, J., Bhattacharya, D., Semmeiroth, I., Bibeau, C. \& Melkonian, .1. 1994. Prasinophytes form independent lineages within the Chlorophyta: evidence from ribosomal RNA sequence comparisons. J. Phycol. 30:340-5.
Swofford, D. L. 1993. PACP: Phylogenetic Analysis Using Parsimony, V3.1.1, Illinois Natural History Survey, Champaign, $117 \mathrm{pp}$.

Tangen, K. \& Björnland, T. 1981. Observations on pigments and morphology of Gyrodinium aureolum Hulbert, a marine dinoflagellate containing 19'-hexanoyloxyfucoxanthin as the main carotenoid. J. Plankton Res. 3:389-40l.

Taylor, F. J. R. 1976. Flagellate phylogeny: a study in conflicts. J. Protozool. 23:28-40.

Turner, S. 1994. Is substitutional bias truly a problem in the inference of chloroplast phylogeny? International Society for Evolutionary Protistology 10, Halifax, Nova Scotia, August 4-10.

Turner, S., Burger-Wiersma, T., Giovannoni, S. J., Mur, L. R. \& Pace, N. R. 1989. The relationship of a prochlorophyte Prochlorothrix hollandica to green chloroplasts. Nature (Lond.) $337: 380-2$

Urbach, E., Robertson, D. \& Chisholm, S. W. 1992. Multiple evolutionary origins of prochlorophytes within the cyanobacterial radiation. Nature (Lond.) 355:267-70.

Valentin, K. \& Zetsche, K. 1990a. Rubisco genes indicate a close phylogenetic relation between the plastids of the Chromophyta and Rhodophyta. Pl. Mol. Biol. 15:575-84.

$1990 \mathrm{~b}$. Structure of the Rubisco operon from the unicellular red alga Cyanidium caldarium: evidence for a polyphyletic origin of the plastids. Mol. Gen Genet. 222:425-30.

Wainright, P. O., Hinkle, G., Sogin, M. L. \& Stickel, S. K. 1993. Monophyletic origins of the Metazoa: an evolutionary link with the fungi. Science (Wash. D.C.) 260:340-2

Watanabe, N. M., Sasa, T., Suda, S., Inouye, I. \& Takaichi, S. 1991. Major carotenoid composition of an endosymbiont in a green dinoflagellate, Lepidodinium viride. J. Phycol. (Suppl.) $27: 75$.

Whatley, J. M. 1993a. Chloroplast ultrastructure. In Berner, T. [Ed.] Ultrastructure of Wicroalgae. CRC Press, Boca Raton, Florida, pp. 135-204.

- 1993b. Membranes and plastid origins. In Lewin, R. A [Ed.] Origins of Plastids. Chapman and Hail, New York, pp. 77-106.

What ey, J. M., John, P. \& Whatley, F. R. 1979. From extracel lular to intracellular: the establishment of mitochondria and chloroplasts. Proc. R. Soc. Lond. B 204:165-87.

What ey, J. M. \& Whatley, F. R. 1981. Chloroplast evolution. New Phytol. 87:233-47.

Wilhelm, C. 1988. The existence of chlorophyll $c$ in the chl $b-$ containing, light-harvesting complex of the green alga Mantoniella squamata (Prasinophyceae). Bot. Acta. 101:7-10.

Wilmotte, A., Turner, S., Van de Peer, Y. \& Pace, N. R. 1992. Taxonomic study of marine oscillatoriacean strains (Cyanobacteria) with narrow trichomes. II. Nucleotide sequence analysis of the $16 \mathrm{~S}$ ribosomal RNA.J. Phycol. 28:828-38.

Woese, C. R. 1987. Bacterial evolution. Microbiol. Rev. 51:22171.

Wolfe, G. R., Cunningham, F. X., Durnford, D., Green, B. R. \& Gantt, F. 1994. Evidence for a common origin of chloroplasts with light-harvesting complexes of different pigmentation. Nature (Lond.) $367: 566-8$.

Zhou, Y. H. \& Ragan, M. A. 1993. CDNA cloning and characterization of the nuclear gene encoding chloroplast glyceraldehyde-3-phosphate dehydrogenase from the marine red alga Gracilaria verrucosa. Curr. Gen. 23:483-9. 